\title{
PERVIVENCIA DE LAS FOSAS COMUNES DE LA GUERRA CIVIL ESPAÑOLA EN EL SIGLO XXI. EVIDENCIA CULTURAL, PARTICULARIDAD ACADÉMICA
} SURVIVAL OF THE COMMON GRAVES
OF THE SPANISH CIVIL WAR IN THE 21ST CENTURY.
CULTURAL EVIDENCE, ACADEMIC PARTICULARITY

Queralt Solé*

Universitat de Barcelona

\begin{abstract}
RESUMEN: En el presente artículo se desarrolla una aproximación a las diferentes formas de producción cultural e histórica que se han realizado en España en torno a las fosas comunes de la guerra civil española en el siglo XXI. Se realiza una breve descripción de las diversas producciones culturales aparecidas en relación con este tema y se expone la incidencia que han tenido las exhumaciones de fosas en los estudios académicos, sobre todo en el ámbito de la historia. Se numeran las universidades e investigadores que han trabajado las fosas comunes como unidad de análisis y se reflexiona respecto a la contribución al conocimiento que los datos históricos de las exhumaciones pueden aportar para la comprensión de los procesos represivos franquistas.

PALABRAS CLAVE: guerra civil española; fosa común; exhumación; represión política; franquismo.

ABSTRACT: In the present article an approximation is made to the different forms of cultural and historical production that have taken place in Spain around the mass graves of the Spanish civil war in the 21st century. A brief description is given of the different cultural productions that appeared in relation to each other and the incidence of the exhumations of mass graves in academic studies, especially in the field of history. Universities and researchers who have worked on mass graves as a unit of analysis are described and the contribution to historical knowledge of historical data that exhumations can contribute to the knowledge of Franco's repressive processes is reflected.
\end{abstract}

KEYWORDS: Spanish Civil War; mass grave; exhumation; political repression; Francoism.

* Correspondencia a: Queralt Solé Barjau. Departamento de Historia y Arqueología. Facultad de Geografia e Historia. Universitat de Barcelona. C/Montalegre 6-8, 08001 Barcelona - queraltsole@ub.edu - https://orcid.org/0000-0001-61284519.

Cómo citar: Solé, Queralt (2019). «Pervivencia de las fosas comunes de la Guerra Civil española en el siglo XXI. Evidencia cultural, particularidad académica»; Historia Contemporánea, 60, 439-475. (https://doi.org/10.1387/hc.20312).

Recibido: 3 octubre, 2018; aceptado: 7 febrero, 2019.

ISSN 1130-2402 - eISSN 2340-0277 / (C) 2019 UPV/EHU

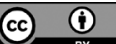


«¿Por qué me miráis así? ¿Es que no habéis comprendido todavía? ¿Cuánto tiempo más necesitaréis para poneros en el punto de vista de la historia? (Su índice señala al fondo de la fosa, como si eligiese a doce hombres.) No es mi mano la que os elige, es la historia la que os ha señalado. Es la historia quien decide qué debe vivir y qué debe morir. ¿Qué vale una docena de hombres frente a la humanidad? (Se vuelve hacia el muro, dando la espalda a la fosa. Los otros internos se vuelven con él. Cual si ocupase la proa de un buque, arenga a los que lo esperan en el puerto. Sus palabras se alzan por encima de olas enormes.) ¡Combatimos por una causa universal! Hermanos obreros y campesinos, ¡nuestra lucha es la vuestra! ¡Aquí estamos, poetas marineros, convocados a cavar la tumba del fascismo! (Señala la rama del naranjo seco.) ¿No luce más bella que nunca la bandera de la República? [...] (Todos escuchan a Cal. En las manos de Benet, el viento deshace el manuscrito de «Entre Naranjos».)»

JUAN MAYORGa, El jardín quemado, 54-55

Desde que se exhumó la que se considera la primera fosa común de la guerra civil excavada con metodología científica en Priaranza del Bierzo (León) el año 2000, las fosas comunes, y con ellas toda su complejidad, se han convertido en una materia que ha ido adquiriendo mayor entidad con el paso del tiempo. Posiblemente los medios de comunicación e internet han contribuido a ello, haciendo que mucha gente quizá se aproximase por primera vez a través de estas a la guerra civil y a la violencia que se desató entonces. Es una temática que ha alcanzado gran resonancia social, aunque consideramos que no tanta a nivel académico, un ámbito donde es materia interdisciplinar. Su influencia en la sociedad no es difícil de percibir a través de las diferentes formas de producción cultural aparecidas desde el año 2000 y en algunos entornos incluso con anterioridad. En este artículo se describen algunos ejemplos de estas creaciones culturales a través de los que se pretende mostrar cómo ha sido una cuestión abordada de forma deficiente a nivel político, mientras que la sociedad la ha adoptado y absorbido expresándolo de muy diversas formas, tanto por medio de creadores y artistas diversos, que son un reflejo de los intereses e inquietudes sociales, como a través de una demanda creciente de estas creaciones. Unas evidencias culturales más acentuadas y visibles que las que se están generando dentro del medio académico, en especial desde el ámbito de la historia. Al respecto, es conocida la bibliografía existente centrada en la represión franquista desde los años ochenta, incrementada a par- 
tir de finales de los noventa. ${ }^{1}$ Así mismo, se trata de una bibliografía que, por suerte, no se ha generado únicamente desde la academia, sino que han sido muchas las investigaciones que se han desarrollado fuera del ámbito universitario y de las que a menudo la academia se nutre. Pero consideramos que, a pesar de las innumerables publicaciones, el más que evidente interés social respecto a las fosas no se ha visto reflejado suficientemente en la investigación universitaria desde el año 2000, donde las fosas comunes en general no son tratadas como un sujeto histórico particular ni que pueden ser consideradas por sí mismas como fuente histórica y complementaria a la fuente documental $\mathrm{u}$ oral.

Hasta el momento no existe ninguna investigación o publicación que haya recogido las producciones culturales aparecidas a partir de las exhumaciones de fosas comunes de la guerra civil. Para paliar en alguna medida este vacío, este artículo se ha estructurado en tres partes diferenciadas, las dos primeras, mayoritariamente descriptivas.

En las siguientes páginas - primera parte del texto-, no se pretende realizar una presentación exhaustiva de estas creaciones culturales ni tampoco un análisis teórico al respecto, cuestión que consideramos que merece varias tesis doctorales desde diversas disciplinas. Simplemente se desarrolla una primera exposición de algunas de estas obras para que sirvan como ejemplo y base de lo defendido: que las expresiones culturales, entendidas de forma muy amplia, demuestran la importancia que han tenido y mantienen las fosas comunes y sus exhumaciones para la sociedad.

La segunda parte del artículo, también eminentemente descriptiva, expone los grupos y personas que en el seno de la academia han investigado las fosas comunes como unidad de análisis, mostrando una fotografía del momento actual [2018] que refleja en el ámbito académico el evidente interés social que a nuestro parecer existe sobre el tema.

La última parte, más breve y analítica, intenta proponer una primera reflexión respecto al porqué el interés del mundo académico no es un espejo del de la sociedad en las fosas comunes. Un interés que, a lo largo de los años, se ha ido transformando y enriqueciendo de otros procesos, haciendo que la demanda de los familiares y de la sociedad se haya acabado delimitando bajo tres términos usados a nivel internacional y que, como globalidad, adquieren una gran fuerza: «Verdad, justicia y reparación».

${ }^{1}$ Los libros que recogen estas investigaciones de forma más detallada son Espinosa, 2010, y Preston, 2011. 


\section{La apertura de las fosas: el estallido de la memoria y su materialidad}

Cuando en el año 2000 se abrió la fosa de Priaranza del Bierzo (León) con metodología arqueológica y con la participación de forenses, se estableció un camino que fijó formas de actuación en todos los sentidos. Unas exhumaciones que fueron y son el punto de partida de la mayoría de la producción de conocimiento posterior, así como de expresiones culturales, en cualquiera de sus formatos posibles. Las exhumaciones de fosas de víctimas de la guerra civil son el núcleo de la voluntad de muchas personas de conocer su pasado más reciente, del que tienen la percepción que les ha sido secuestrado.

En las exhumaciones ya se percibe esa interdisciplinariedad que posteriormente encontramos en las producciones científicas y culturales: investigación histórica; arqueología; antropología física, cultural y forense; biología genética; el papel de la justicia y el derecho; psicología; periodismo... Desde todos estos ámbitos, y desde algunos otros, han aparecido publicaciones divulgativas o académicas y expresiones culturales muy diversas.

Podemos empezar el breve recorrido por las expresiones culturales que nos proponemos presentar por la escultórica, que consideramos muy significativa, pues sustituye una materialidad y un espacio por otros: unos agujeros en la tierra o unos huesos desenterrados son sustituidos o representados por piedra, mármol, hierro, etc. Y la escultura pasa a ocupar el espacio en el que estaba la fosa, o bien se instala en un lugar en el que la visualización del recuerdo de la violencia de la guerra sea aun mayor.

La política simbólica visibiliza a la sociedad la existencia y exhumación de unos restos óseos sin sepultura digna, mantenidos bajo tierra durante decenios, para hacer emerger en su lugar un espacio plagado de historia, memoria, sentimientos y emociones. ${ }^{2}$

Antes del año 2000, ya existían representaciones artísticas - en las que no contemplamos los monolitos - en fosas comunes, pero durante los primeros años del siglo XXI han surgido más. ${ }^{3}$ Se quieren destacar tres obras entre muchas otras. ${ }^{4}$

\footnotetext{
2 Alonso Carballés, 2013.

3 Por ejemplo, en el cementerio de Barcelona, véase Conesa, 2013; o en el cementerio de Oviedo, en Viudas de los Defensores de la República y del Frente Popular de Asturias, 1988.

${ }^{4}$ Otros ejemplos destacados: en el cementerio de Jaén, se inauguró una escultura en 2007; en Carrocera (León), en 2008 se inauguró fuera del cementerio una escultura en re-
} 
En noviembre del año 2011, en la fosa de La Barranca de Lardero (La Rioja), se inauguró un grupo escultórico titulado Mujeres de negro, cuyo autor es Óscar Cenzano. El simbolismo pretendía ser y es claro: recordar a todas las mujeres que, de luto, mantuvieron el recuerdo vivo de sus muertos yendo como mínimo cada $1 .^{\circ}$ de noviembre al lugar donde habían sido mal sepultados sus seres queridos. ${ }^{5}$ Otros dos ejemplos de política simbólica son el Parque de la memoria, de Sartaguda, en Navarra, y las esculturas del valle del Jerte, en Cáceres. En el primero son diversas las monumentales esculturas realizadas por diferentes artistas, todas ellas emplazadas en un parque, seleccionado por ser testigo de la fuerte represión sufrida por este municipio navarro al que se llegó a conocer como «el pueblo de las viudas». 6

En 2009, cuatro figuras humanas fueron ubicadas en el término municipal de El Torno (Cáceres), en un lugar desde el que se puede contemplar todo el valle del Jerte y que pasó a denominarse El Mirador de la Memoria, obra del escultor Francisco Cedenilla. Impactan su singularidad y significado, puesto que a través de esas cuatro figuras - un joven, un adulto, un anciano y una mujer - emplazadas sobre unas rocas, se trata de representar a los olvidados de la guerra civil. El grupo escultórico fue tiroteado horas después de su inauguración, ultrajándolo, un hecho que se repite a menudo a lo largo del Estado hacia estas obras conmemorativas o artísticas en recuerdo y homenaje de las víctimas de la represión franquista. Las noticias al respecto gotean de manera incesante y hacen patente una realidad que no es fácil aceptar: la división ideológica entre vencedores y vencidos de una guerra civil de hace ochenta años, tras cuarenta años de franquismo y cuarenta más de democracia, aún pervive.

En este mismo ámbito de política simbólica se debe destacar que, aparte de las obras permanentes, también son frecuentes las expresiones artísticas de las que queda poco rastro, o que solo encontramos en la red, y que han tenido repercusión básicamente en el momento de ser re-

cuerdo a los represaliados de la dictadura franquista; en el cementerio de Tarragona, desde 2010, una escultura de hierro recuerda a los que allí fueron enterrados después de ser fusilados; y en 2016, en Benavente (Zamora), se inauguró otra en el cementerio. Es posible encontrar muchas otras obras por toda la geografía española.

5 Asociación La Barranca, <http://labarranca.org/>. [Todas las páginas webs referenciadas han sido verificadas en enero de 2019.]

6 Jimeno Jurío, Mikelarena, 2008. Véase información del parque en <www.parquedelamemoria.org $>$. 
presentadas o llevadas a cabo. En octubre de 2017, Iratxe Jaio y Klaas van Gorkum, artistas visuales, llevaron a cabo lo que titularon La ruta más larga, que se pregunta y cuestiona qué hacer con los restos de soldados desconocidos, exhumados de fosas en la línea de frente y de los que actualmente nadie se responsabiliza. ${ }^{7}$ Fernando Sánchez Castillo es otro artista que destaca por la forma original y novedosa de recordar la represión y repercusión de la guerra civil en sus obras. Para Síndrome de Guernica compró el yate Azor, un símbolo franquista evidente, y lo transformó en un bloque de chatarra. ${ }^{8}$ Tiene más creaciones que intentan plasmar aquello que no somos capaces de articular con palabras, esa indecibilidad que permite pensar y explorar los hechos de forma singular e innovadora. Son formas expresivas que quieren superar la incapacidad de relatar con palabas un pasado que, en pleno siglo XXI, sigue siendo difícil de abordar sin dolor por parte de muchas personas y que requieren de todos nuestros sentidos.

La fotografía, otra forma de expresión artística, ha ido ganando terreno en estos primeros años del siglo XXI. Diversos fotógrafos han realizado exposiciones con imágenes tomadas a pie de fosa, como Francesc Torres con «Oscura es la habitación donde dormimos», Clemente Bernard con «Donde habita el recuerdo», o Gervasio Sánchez con «Desaparecidos». ${ }^{9}$ Imágenes que pretenden recoger una realidad que no puede ser preservada si no es dotándola de valor documental, y a la que añaden su visión particular, un punto de vista que trata de ir más allá de la captura de una instantánea y quiere ser una imagen representativa.

La música es otra forma de expresión cultural que llega a donde no lo hacen el sentido de la vista o el tacto; canciones que parecen poemas musicados. Esta forma artística también ha irrumpido con fuerza, expresando lo que sucede y se experimenta emocionalmente en las exhumaciones a través de melodías. Se pone música y voz a huesos, cerebros y corazones exhumados, como hacen Maria Arnal y Marcel Bagés en el disco 45 cerebros y 1 corazón, cuyos conciertos en 2018 por todo el Estado han cose-

7 Jaio, Van Gorkum, 2017, <https://www.teklak.org/iratxe-jaio-klaas-van-gorkum>.

8 Véase una explicación del proceso y la exposición final en la web de El Matadero de Madrid, <http://www.mataderomadrid.org/ficha/1203/fernando-sanchez-castillo.html>. Algunas de sus otras obras o performances han sido realizadas y recogidas en la web del Museo de Arte Contemporáneo de Lima, http://li-mac.org/es/collection/limac-collection/fernando-sanchez-castillo/

9 Torres, 2007; Bernard, 2010; Sánchez, 2011. 
chado un éxito de público. ${ }^{10}$ El título del álbum es también el de una canción que recoge lo que sucedió en la exhumación de La Pedraja (Burgos) el año 2010, cuando se desenterraron 45 cerebros saponificados y un corazón, órganos humanos de víctimas republicanas que, debido a la composición del suelo y el clima, se fueron preservando y transformado a pesar del paso del tiempo. Un caso único en el mundo. ${ }^{11}$

Sobre las personas asesinadas y enterradas en fosas también canta Pedro Guerra en su canción de título explícito Huesos, al igual que Lucía Sócam, quien expresa las emociones que revelan sus canciones durante las exhumaciones de fosas en su libro-CD Verdades Escondidas. ${ }^{12}$ En él hay temas con títulos tan evidentes como Todos los nombres, Las 17 Rosas de Guillena o Campo de concentración de Castuera. Toda su discografía es, de hecho, un grito a la memoria y a la reivindicación de esta. Pero no solo se ha escrito y tocado música por parte de cantautores. Grupos como la banda de rock y heavy metal Barricada, publicaron en 2009 un álbum conceptual con el título de La tierra está sorda, cuyas canciones estaban todas ellas dedicadas a la guerra civil y más de una focalizada en las fosas comunes, como la canción Por la libertad..$^{13} \mathrm{El}$ álbum consiguió el Disco de Oro en 2009. También el grupo valenciano La Raíz, cuyo estilo pasa por el rock, ska, reggae, folk o rap y que en 2016 publicaron el disco Entre poetas y presos. La canción que da nombre al disco tiene una letra reivindicativa y las fosas son las protagonistas: «Somos los hijos de los versos / de los poetas y los presos, / la voz que grita entre los huesos / de las cunetas para despertar / al universo». ${ }^{14}$

Una expresividad artística en la que también encontramos el pasado representado es el teatro. En 1996, el dramaturgo Juan Mayorga escribió El jardín quemado, del que se reproduce una pequeña escena al principio de este texto. ${ }^{15}$ En tres espacios escénicos se desarrolla el encuentro entre un joven Benet y el director del sanatorio de San Miguel, llamado Cal. Sucede durante la Transición, y la mayoría de la acción tiene lugar en el jardín del sanatorio, un lugar gris y triste por donde van deambulando los

10 Arnal, Bagés, 2017.

11 Serrulla, et al., 2016; Serrulla Rech, 2018.

12 Guerra, 2013; Sócam, 2010.

13 Barricada, 2009. El videoclip está disponible en YouTube: <https://www.youtube. $\mathrm{com} /$ watch?v=LUYIaDFbm3U>.

${ }^{14}$ LA RAIZ, 2016.

15 Mayorga, 2008. 
internos. El joven investiga el asesinato en el psiquiátrico, durante la guerra, de un célebre poeta republicano y otros once hombres, convencido de que el director los había asesinado. Sin embargo, al final acaba descubriendo que los doce hombres continúan internados en el sanatorio, enloquecidos. Y descubre que Cal les obligó, cuarenta años atrás, a entregarse o a elegir a otros internos para que fuesen ellos los ajusticiados, víctimas que aún yacen enterradas en una fosa común en el mismo hospital. ¿Conocía Juan Mayorga la existencia de la fosa de Valdediós (Asturias) cuando escribió en 1996 la obra? Curiosamente, la obra de teatro es muy similar a la historia real de la fosa asturiana, donde la madrugada del 28 de octubre de 1937 un batallón franquista mató a diecisiete trabajadores del monasterio, habilitado en esos momentos como hospital. Eran once mujeres y seis hombres. «Catorce tenían el cráneo fracturado como consecuencia de los disparos de arma de fuego, en todos los casos de fusil, generalmente recibidos cerca del oído. En el caso de los hombres, aparecen además otros disparos en otras partes del cráneo.» ${ }^{16}$

Mayorga escribió El jardín quemado antes de que se abriera la fosa de Priaranza en el año 2000. Antes de la primera exhumación, desde el teatro se reflexionaba, se hablaba, se ponía sobre la escena el pasado incómodo y se preguntaba al espectador. Y se habían escrito muchas obras donde la fosa común está siempre presente, explícita o implícitamente. ${ }^{17}$ En 2005, Juan Capote presentó Soliloquio de grillos, que el autor escribió cuando conoció la exhumación de una fosa de tres mujeres en Candeleda (Ávila). ${ }^{18}$ En 2008, el Memorial Democràtic de la Generalitat de Catalunya premió la obra de Joan Cavallé, Peus descalços sota la lluna d'agost, donde se cuestiona la violencia gratuita, la necesidad de olvidar lo sucedido y, paralelamente, recuperar lo perdido. ${ }^{19}$ Se han estrenado más obras - muchas más - que las referenciadas, e incluso hay que destacar que ya existe una tesis doctoral que analiza la representación teatral de la memoria, que abarca desde los inicios del franquismo hasta el año 2009. ${ }^{20}$ La autora no pudo analizar por lo tanto una gran producción estrenada en 2017, en Madrid, Donde el bosque se espesa, de la compañía Micomicon, y que es el resultado de un trabajo conjunto entre esta y el grupo

\footnotetext{
16 De la Rubia Barbón, De la Rubia Huete, 2006.

17 Amo Sánchez, 2012, 2014; Sansano, 2014.

$18<$ http://www.profesionalespcm.org/_php/MuestraArticulo2.php?id=6928>.

19 Cavallé, 2009.

20 Guzmán, 2012.
} 
académico de investigación europeo Unrest. ${ }^{21}$ Son obras que forman parte de un «teatro histórico crítico que hace visible heridas del pasado que la actualidad no ha sabido cerrar. Hace resonar el silencio de los vencidos, que han quedado al margen de toda tradición. En lugar de traer a escena un pasado que conforte al presente, que lo confirme en sus tópicos, invoca un pasado que le haga incómodas preguntas». ${ }^{22}$

Y del teatro a la pantalla, ya sea en televisión o en cines. ${ }^{23}$ También se han hecho documentales donde las fosas comunes tienen un papel importante en el argumento, así como programas de entretenimiento que no por tener este epíteto dejan de ser rigurosos ${ }^{24}$ y es que «el imaginario colectivo más reciente sobre la guerra civil española le debe más a la televisión que al cine, a pesar de la importancia del medio cinematográfico a este respecto en décadas anteriores». ${ }^{25}$

En televisión, en canales estatales o autonómicos, se han realizado documentales con elevados niveles de audiencia y que significaron el desvelamiento de unos hechos hasta entonces insuficientemente explicados, como Las fosas del silencio, del que posteriormente se publicó un libro. ${ }^{26}$ Las fosas del olvido, ${ }^{27}$ Un silencio roto, ${ }^{28}$ o Las heridas de la guerra civil, ${ }^{29}$ por citar solo algunos, tratan esta cuestión desde una perspectiva general.

En ese sentido, posiblemente cada una de las fosas abiertas desde el año 2000 merecería un documental como espacio de memoria, pues este tipo de soporte ayudaría a llenar esa carencia, y su realización formaría parte de la triple demanda de los familiares de «Verdad, justicia y

${ }^{21}$ Donde el bosque se espesa, Compañía Micomicon, escrita por Laila Ripoll y Mariano Llorente, y dirigida por Laila Ripoll. Proyecto europeo «Unsettling Remembering and Social Cohesion in Transnational Europe», en $<\mathrm{http}: / / \mathrm{www}$.unrest.eu/> y $<\mathrm{http}: / / \mathrm{cchs}$. csic.es/es/article/estreno-teatro-donde-el-bosque-se-espesa>.

22 Mayorga, 2015.

23 Caparrós, Crusells, Barba, 2016; Breu, 2016.

${ }^{24}$ Un claro exponente es la serie documental «El lector de huesos», de EiTB, 2016, protagonizada por el médico forense de la Universidad del País Vasco Francisco Etxeberria. Véase la web de la serie de reportajes en <https://www.eitb.eus/es/television/programas/el-lector-de-huesos//>.

${ }_{25}$ Gutiérrez Lozano, Sánchez Alarcón, 2005.

26 Armengou, Belis, 2004.

27 Domingo, Bernaola, Sánchez, 2004.

28 López, Troyano, 2004.

29 Las heridas de la guerra civil, «60 minutos», EITB, 2014. 
reparación». ${ }^{30}$ No todas las fosas lo tienen, pero sí se realizó uno de las exhumaciones del Fuerte de San Cristóbal (Pamplona), del que también se hizo un libro, a parte de la canción compuesta por Barricada ya citada. ${ }^{31}$ La fosa de las diecisiete mujeres de Guillena, asesinadas y enterradas en Gerena (Sevilla), también cuenta con un documental, ${ }^{32}$ del mismo modo que la exhumación del cementerio de Málaga es el eje conductor en el film Sombra en el paraíso. ${ }^{33}$ Son tan solo algunos ejemplos de los muchos audiovisuales que se localizan por todo el Estado y que no dejan de producirse y también de ganar premios, como Cunetas ${ }^{34}$ o El silencio de otros. ${ }^{35} \mathrm{Se}$ trata de fórmulas de trasladar a la pequeña pantalla la historia y la memoria y que han sido analizadas por especialistas diversos, al igual que algunas series que en su momento también tuvieron un éxito destacado y que, a pesar de que en ellas no se explicitó el tema de las fosas, sí centraban su argumento en la guerra civil y la dictadura franquista. ${ }^{36}$

Asimismo, las exposiciones se encuadran como expresiones artísticas visuales. En una sociedad en la que impera la imagen, las exposiciones - con imagen y discurso - son otro recurso para llegar a la población y mostrar o representar todo lo que supone la apertura de una fosa común de la guerra civil.

Las diversas asociaciones de memoria de todo el territorio español han sido las que más exposiciones han producido, esforzándose para que recorran pueblos y ciudades y den a conocer su tarea ${ }^{37}$ Con frecuencia, una vez han sido expuestas, estas muestras no desaparecen por completo, sino que se pueden encontrar reproducidas en las páginas web de las mismas entidades, que mantienen una voluntad de concienciación, difusión y divulgación de las fosas exhumadas de la guerra civil y del significado que tiene su excavación.

30 Ferrándiz, 2014.

31 Etxeberria, Pla, 2014.

32 Agudo, 2013.

33 Jiménez Real, 2009.

34 Teixidor, 2017.

35 Carracedo, Bahar, 2018. 2009.

36 Hernández Corchete, 2008; Rueda Laffond, 2008; López, Cueto, George (Eds.),

37 Sirvan como ejemplos la de «Exhumando fosas, recuperando dignidades», de la Sociedad de Ciencias Aranzadi; o la del fotógrafo Sergi Bernal, «Desenterrando el silencio», centrada en un maestro exhumado de una fosa de La Pedraja, en Burgos, de la que también se hizo un libro <http://desenterrant.blogspot.com.es/>. 
Y finalmente no podemos olvidarnos de los libros. Los primeros que se publicaron cuyo protagonismo se centraba en las fosas - siendo el eje de la publicación su apertura y los restos exhumados en este siglo XXI- fueron escritos por periodistas. Hasta entonces, en muy pocas ocasiones las fosas habían sido el sujeto principal de análisis, y tan solo había referencias, mayormente tangenciales a ellas, en algunos libros de historia de los años ochenta y noventa. ${ }^{38}$ Santiago Macías y Emilio Silva sacaron a la luz en 2003 Las fosas de Franco. Los republicanos que el dictador dejó en las cunetas. ${ }^{39}$ En el volumen, los autores relatan cómo llegaron a poder exhumar la fosa de Priaranza del Bierzo, en León. Su punto de vista es periodístico y no histórico, y por lo tanto la aproximación que hicieron al tema se realizó desde un punto de vista informativo, priorizando el hecho de dar a conocer la existencia de las fosas de la guerra civil, más que adentrarse en cuestiones analíticas. Este tipo de aproximación periodística a la cuestión de las fosas ha sido constante desde la primera apertura, un hecho que por otro lado es muy comprensible. El periodismo nunca se ha alejado ni ha dejado de hacer de caja de resonancia de la apertura de fosas. No hay duda de que el interés que ha generado y se ha trasladado a la sociedad ha resultado muy beneficioso para aquellas personas que buscaban a sus familiares desaparecidos, al evidenciar la situación en la que se encuentran, y ha sido un elemento de difusión básico, así como representa una constatación del interés social que suscitan: si se buscan, escriben y emiten noticias, se redactan artículos, se publican opiniones al respecto..., es porque toda la cuestión de las fosas y la memoria histórica son temas que interesan a la sociedad. De hecho, fueron publicaciones periódicas las que, tras la muerte del dictador, informaron de las exhumaciones que empezaron el mismo año de 1975 y que ya no se han dejado de realizar hasta la actualidad. La revista Interviú realizó reportajes al respecto desarrollados por Francisco Ferrándiz y Paloma Aguilar. ${ }^{40}$ Hasta hace poco se creía que con posterioridad al intento de golpe de Estado de 1981 estas exhumaciones de la transición habían dejado de realizarse, pero estudios recientes parecen desmentir esta lectura. ${ }^{41}$

38 Gibson, 1975; Solé i Sabaté, Villarroya, 1984; Cabrera Acosta, 1985; Moreno Gómez, 1985; Asociación de Viudas de los Defensores de la República y del Frente Popular de Asturias, 1988; Altafaylla Kultur Taldea, 1986; Gimeno, 1987; Ortiz Villalba, 1988; Barallat, 1991; García Luis, 1994.

39 Silva, Macías, 2003.

40 Ferrándiz, Aguilar, 2016.

41 De Kerangat, 2017. 
Como se ha comentado, del documental Las fosas del silencio apareció posteriormente un libro, pero también puede destacarse el de Natalia Junquera, pues constituyen ejemplos del interés que el periodismo mantiene sobre las publicaciones de monografías sobre esta temática, y que asimismo observamos respecto a la que se ha pasado a denominar «la mayor fosa común» existente en la actualidad: el Valle de los Caídos. ${ }^{42} \mathrm{~A}$ pesar de las numerosas publicaciones de los últimos años ${ }^{43}$ destaca el hecho de que el primero en aproximarse al monumento fue el periodista Daniel Sueiro, en 1977, analizando su significado y cómo había podido ser construido, así como los costes o los restos humanos que podía contener. ${ }^{44}$

La literatura es otra de las expresiones culturales que sirven de espejo de los intereses de la sociedad, y las fosas también se han reflejado en ella. A finales de los años noventa del siglo pasado empezaron a publicarse novelas relacionadas con la guerra civil y la posguerra. No es que antes no se hubiesen escrito, pero los autores empezaron a cambiar las características de sus novelas: dejaron de tener una vinculación directa con los hechos, recogieron experiencias y memorias ajenas e intentaron distanciarse ideológicamente de los sucesos que narraban o en los que se inspiraban. ${ }^{45}$

En Soldados de Salamina, ${ }^{46}$ una fosa común que el protagonista logra evitar se mantiene siempre presente, amenazante; en Las trece rosas ${ }^{47}$ o Trece rosas rojas, ${ }^{48}$ el fusilamiento de trece chicas, que fueron fusiladas a la vez, es el eje central de las dos novelas; Enterrar a los muertos ${ }^{49}$ narra la búsqueda de un ausente en mitad de la guerra, alguien que nadie entiende por qué ha desaparecido; sobre muertos y desapariciones también habla Fantasmas del Invierno, una novela tremendamente dura que se centra en la posguerra, en los fantasmas, en lo destruido, en lo olvidado y en el no-futuro..$^{50} \mathrm{Y}$ como estos, existen tantos otros ejemplos en los que la ausencia, la desaparición, la muerte, el olvido y el recuerdo constitu-

42 Junquera, 2013.

43 Aguilar, 1993; Solé, 2008, 2017; Olmeda, 2009; Crumbaugh, 2011; Bárcena, 2012;

Stockey, 2013; Hepworth, 2014; Quintana, 2018.

44 Sueiro, 1976.

45 Izquierdo, 2012.

46 Cercas, 2001.

47 Ferrero, 2003.

48 Fonseca, 2004.

49 Martínez de Pisón, 2005.

50 Mateo Díez, 2004. 
yen el eje de las historias que los escritores no paran de crear y los lectores de demandar. Un ámbito literario sobre la memoria que ha sido profusamente estudiado, en este caso también desde la academia, posiblemente porque desde muy pronto empezaron a surgir obras literarias, incluso durante la misma guerra y justo después, lo que ha permitido que exista una extensa antología para analizar y comparar, así como para trazar una perspectiva temporal. ${ }^{51}$

La influencia de la guerra en la literatura es un ámbito en el que la producción académica se mantiene continua, pues se trata de una temática que despierta un gran interés en la academia, tanto dentro como fuera de España. ${ }^{52}$

\section{Las fosas comunes de la guerra civil y la historiografía: incidencia en el relato académico}

A pesar de lo expuesto anteriormente, donde se ha querido destacar la gran producción cultural existente en algunos ámbitos artísticos, el hecho de que la apertura de una fosa común de la guerra, y todo lo que significa, sea un ejemplo de materialidad de un pasado traumático asumido por gran parte de la sociedad, aún no ha repercutido con fuerza en el mundo académico de la historia.

Las fosas comunes de la guerra civil son una fuente histórica que refuerza y amplía los años de investigaciones y publicaciones previas, centrados en la represión franquista y basados sobre todo en el estudio de la documentación y en las referencias aportadas por las fuentes orales. Toda la información contenida en una fosa de civiles asesinados, de prisioneros ejecutados o de soldados enterrados en una fosa común, se trata como datos analizables desde muy diversos ámbitos, y la fosa en sí misma, la materialidad ósea y todos los objetos que la acompañan, es una fuente que también se enriquece del hecho de ser investigada desde la interdisciplinariedad. Cualquier informe nacido del estudio de alguno de los elementos que conforman una fosa común es susceptible de interés para el historiador, ya sea desde el ámbito arqueológico, forense o psicológico. La asunción de estos como parte de los instrumentos de análisis histórico para el

51 Trapiello, 2010.

52 Cuñado, 2007; Faber, 2011; Potok, 2012. 
estudio de la represión resulta en estos momentos imprescindible y, como veremos a continuación, se ha trabajado al respecto $-\mathrm{y}$ en algunas universidades de forma muy extensa -, aunque, comparativamente con la repercusión social que ha tenido la apertura de las fosas, no deja de ser un eco al que le falta fuerza.

Es cierto que el ritmo de la academia para producir conocimiento es más lento, y que los libros rigurosos y las tesis doctorales necesitan un tiempo de trabajo en profundidad, pero no deja de sorprender que hasta hoy, y desde el año 2000, el relato académico sea aún minoritario. Quizá se deba a ello que las primeras publicaciones que aparecieron con las fosas como eje, y que hemos citado anteriormente, fueran obras de periodistas.

No fue hasta 2008 cuando aparecieron tesis doctorales o libros realizados desde las universidades, en los que se tuvieron en cuenta para la investigación la información derivada directamente de la existencia de las fosas o de su apertura. ${ }^{53}$ Y lo que se ha evidenciado después de esos años es que cualquier libro que analice la violencia durante la guerra ya no puede obviar la información y los datos que aportan los estudios de las fosas y sus exhumaciones, como se demuestra en la tesis de Laura Muñoz Encinar, de la que volveremos a hablar más adelante..$^{54}$

En el ámbito académico se detectan ciertas cuestiones que vale la pena destacar. Una de ellas es que las exhumaciones han generado un gran interés en el mundo de la antropología física. Por otra parte no debería resultar tan extraño, puesto que se están abriendo y exhumando fosas donde los huesos aparecen como la centralidad, ya que son los que nos hablan de manera más explícita sobre la violencia en el pasado. Esto ha provocado que las publicaciones científicas en antropología física al respecto se hayan incrementado, así como las presentaciones en congresos estatales e internacionales de análisis diversos, al mismo tiempo que se ha multiplicado la afluencia de estudiantes a másteres donde se imparte una especialización en la materia. ${ }^{55}$ En ese sentido, destaca la lectura de diversas tesis doctorales centradas en la identificación de restos

53 Solé, 2008.

54 Muñoz Encinar, 2016.

55 Máster Universitario en Antropología Física y Forense de la Universidad de Granada; Máster en Antropología Biológica de la Universitat de Barcelona y la Universitat Autònoma de Barcelona; Máster en Memoria social y Derechos Humanos: Ciencias sociales y forenses ante los conflictos contemporáneos, UNED. 
exhumados o el análisis de las exhumaciones, así como alguna publicación que puede interpretarse como un estado de la cuestión en lo que se refiere a este tema. ${ }^{56}$

A nivel arqueológico, la implicación por parte de la academia lentamente ha ido a más, y debe citarse el volumen 19 , número 2 , de la revista Complutum (Universidad Complutense de Madrid), del año 2008, como un momento de inflexión al respecto, al publicar un monográfico centrado en la arqueología del conflicto, en el que había diversos artículos focalizados en el análisis de las fosas comunes y que evidenciaba el interés creciente por esta disciplina en las exhumaciones. A pesar de ello, en pocas ocasiones han sido equipos surgidos desde las universidades los que han intervenido en las fosas, ya que la mayoría se nutre de la participación de voluntarios convocados por las familias o las asociaciones, o bien de equipos más o menos estables que responden a las peticiones de exhumación que se lanzan desde esas mismas entidades, lo que no significa que en ellos no puedan colaborar profesores universitarios. ${ }^{57}$ Este hecho ha provocado que cada vez sean más numerosas las publicaciones al respecto desde el mundo de la arqueología, y que se editen en revistas académicas muy dispares..$^{58}$

Otro hecho a destacar, y muy importante a nuestro parecer, ha sido el papel desempeñado individualmente por ciertos docentes de distintas universidades. Cuando un departamento de historia está implicado o tiene relación con las fosas y las exhumaciones, se debe a que uno o diversos profesores alientan y propician que se realicen estudios - institucionales, de

56 Peraza Casajús, 2010; Ríos Frutos, 2012; Fernández de Mata, 2016; García-Rubio, 2017; Serrulla Rech, 2018. Boletín Galego de Medicina Legal e Forense, n. ${ }^{\circ}$ 18, enero de 2012. Recuperado de internet en <http://www.agmf.es/boletines/boletin18.pdf>.

57 Tal como se expone más adelante, fueron equipos universitarios los que exhumaron dos fosas en Cataluña; el equipo de Alfredo González-Ruibal, CSIC-INCIPIT, ha exhumado restos de soldados hallados en las excavaciones del frente que están llevando a término desde hace unos años. Véase Alfredo González-Ruibal, 2016. Algunos equipos de voluntarios, muy dispares entre sí, son los de la Sociedad de Ciencias Aranzadi; el mismo equipo de la ARMH, dirigido por René Pacheco. En el equipo de la Sociedad de Ciencias Aranzadi está Francisco Etxeberria (UPV), o en diversas exhumaciones del Foro por la Memoria ha participado Ermengol Gassiot (UAB), como la de 2007 en Villanueva del Rosario (Málaga).

${ }^{58}$ Las publicaciones más representativas al respecto, además de algunos artículos publicados en otras revistas científicas, son el número 19(2) de 2008 de la revista Complutum, la revista Munibe, en muchos de sus números, así como Ebre’38, a pesar de la discontinuidad de la publicación. 
investigación - al respecto. Existen diversos casos representativos. De entre las universidades de la Comunidad Valenciana destacan, por ejemplo, los profesores José Miguel Santacreu o Gabriel Sansano, de la Universidad de Alicante. Ambos se habían aproximado desde la historia o la literatura y el teatro a la cuestión de la memoria histórica y, en particular, a la de las fosas. Unas temáticas que, a partir del cambio de gobierno en la Comunidad, se han podido beneficiar del apoyo institucional y que se han concretado en la creación de una Cátedra Interuniversitaria que, junto con la Consejería de Justicia, ha reunido de forma interdisciplinar a aquellos profesores que, desde Alicante, la Universitat Jaume I de Castellón (Rosa Monlleó Peris) y la Universitat de València (Javier Navarro Navarro) hacía tiempo que trabajaban en temas de represión. ${ }^{59}$ Desde que empezó su andadura, han sido numerosos los seminarios, congresos y encuentros diversos incentivados, así como la publicación diversos números de una colección de libros específica sobre Memoria Democrática, de la que ya han sido editados tres volúmenes.

El caso de Valencia sirve como paradigma de lo sucedido en otras regiones del Estado: no solo desde la academia se investiga y se aporta conocimiento histórico, sino que asociaciones, entidades, profesores de secundaria o investigadores independientes han estado trabajando y han tenido en cuenta esta nueva fuente. Entre estas aportaciones cabe destacar en la Comunidad la asociación Grup de Recerca de la Memoria de Castelló, que mantiene una actividad constante en su web y publica continuamente estudios sobre la guerra, la represión y las fosas comunes en los que se tienen en cuenta los datos de las exhumaciones. ${ }^{60}$

En octubre de 2017, Valencia aprobó su propia ley de memoria histórica, y solo el tiempo dirá si en el caso valenciano la existencia de la ley es un revulsivo o un freno para un posterior estudio, dignificación, apertura de fosas comunes y sus análisis desde una perspectiva histórica. ${ }^{61}$

En Extremadura, fue Julián Chaves Palacios el que incentivó y mantuvo durante años una continuidad en la investigación histórica respecto a

59 El Partido Popular gobernó en Valencia desde 1999 con mayoría absoluta, sin llevar a término ninguna política pública de memoria y frenando cualquier cuestión relacionada con las exhumaciones. Las tareas al respecto que se realizaron fueron a partir de la aprobación de las subvenciones estatales de 2006.

60 Véase Porcar Orihulea, 2013.

${ }^{61}$ Ley de Memoria Democrática y para la Convivencia de la Comunitat Valenciana, aprobada por las Cortes Valencianas el 19 de octubre de 2017. 
las fosas, las exhumaciones y la represión franquista en todas sus vertientes. Desde el año 2002 hubo un acuerdo entre la Junta y la universidad y se creó el Proyecto de Recuperación de la Memoria Histórica (PREMHEX), que fue pionero en cuanto a sus planteamientos y objetivos. ${ }^{62}$ La colaboración entre diversas entidades, incluidas asociaciones y agrupaciones de familiares, así como la continuidad en las actuaciones - tanto en exhumaciones como en investigación histórica - ha permitido que se exhumasen decenas de fosas y apareciesen sólidas y excelentes tesis doctorales, ${ }^{63}$ como la de Laura Muñoz Encinar, quien ha conseguido llegar a la interdisciplinariedad deseada y reclamada con su tesis, De la exhumación de cuerpos al conocimiento histórico. Análisis de la represión irregular franquista a partir de la excavación de fosas comunes en Extremadura (1936-1948), que ha significado un punto y aparte respecto al análisis interdisciplinar que aportan las exhumaciones. ${ }^{64} \mathrm{Su}$ vertiente como historiadora junto a sus conocimientos y experiencia en arqueología y en antropología física le han permitido elaborar una tesis en la que se puede llegar a nuevas conclusiones respecto a la violencia franquista y en la que la fosa común es considerada como una unidad de análisis. La documentación examinada, junto con la memoria oral y la información preservada en los restos óseos de las víctimas exhumadas de diez fosas, le han ayudado a determinar los lugares en los que los rebeldes y los grupos afines preferían asesinar; las formas de atar o no a las víctimas antes de ser ejecutadas; los zonas del cuerpo donde se disparaba; el uso de armas blancas; las diferentes maneras de enterrar o quemar los cuerpos antes de sepultarlos, así como lo que se pretendía con este castigo visual...; las estrategias de eliminación que se observan en y desde las fosas y que son «el primer eslabón de la cadena del aparato represivo franquista». ${ }^{65} \mathrm{Su}$ tesis reafirma lo apuntado: a partir del momento en que se empieza a exhumar con metodología científica en el siglo XXI y se pueden recopilar las memorias y los resultados de las exhumaciones, ya no es posible analizar la repre-

62 Convenio de colaboración suscrito el 2 de diciembre de 2002 entre la Junta de Extremadura y las Diputaciones Provinciales de Badajoz y Cáceres y la Universidad de Extremadura para la Recuperación de la Memoria Histórica de Extremadura, que se renueva anualmente.

63 Martín Bastos, 2013; Chaves Rodríguez, 2014.

${ }_{64}$ Muñoz Encinar, Chaves Palacios, 2014; Muñoz Encinar, 2016.

65 Muñoz Encinar, 2016, p. 665. Véase asimismo la tesis de Aragüete-Toribio, 2017, leída en la Goldsmiths, University of London, con el explícito título de Producing History in Spanish Civil War Exhumations. 
sión, la violencia franquista y sus formas de actuación sin tener todos esos datos en cuenta.

Pero en Extremadura la relación con el ámbito académico aun ha aportado más. En 2014 se publicó el libro Proyecto de recuperación de la Memoria Histórica en Extremadura: balance de una década (2003-2013). Investigación de la guerra civil y el franquismo. ${ }^{66}$ En el volumen se reúnen los datos empíricos recogidos de registros y archivos (más de 800 páginas), se presenta el mapa de las fosas de Extremadura y se detallan las exhumaciones llevadas a cabo, así como las acciones divulgativas del PREMHEX. Un proyecto realizado íntegramente desde la universidad, en convenio con las instituciones, que plasma las posibilidades de las actuaciones conjuntas con resultados académicos potentes.

En Canarias, donde se aprobó en 2018 una Ley de Memoria Histórica, ${ }^{67}$ profesores o investigadores relacionados con el Departamento de Historia de la Facultad de Geografía e Historia de la Universidad de La Laguna han estudiado desde diferentes enfoques la existencia de fosas, al mismo tiempo que se han exhumado varias de ellas analizando la cuestión desde una perspectiva interdisciplinar, tan necesaria como imprescindible. ${ }^{68}$ En este caso dos jóvenes historiadores, Victorio Heredero Gascueña y Aarón León Álvarez, han trabajado desde una perspectiva histórica la existencia, permanencia y exhumación de fosas de la guerra en el archipiélago. ${ }^{69}$ Junto a otros investigadores canarios, pertenecen a una nueva generación de historiadores, como Laura $\mathrm{Mu}$ ñoz Encinar, que han desarrollado su formación en paralelo a las exhumaciones de fosas y que, a los estudios existentes de represión y violencia franquista realizados en las décadas anteriores, han sumado los datos que aportan todo lo que conlleva el análisis de esta nueva y, años atrás, impensable fuente.

En Galicia no resulta difícil localizar a las personas que desde el ámbito universitario han estado promoviendo y dirigiendo investigaciones diversas, todas ellas agrupadas alrededor del proyecto Nomes e Voces,

${ }^{66}$ Chaves Palacios, et al., 2014.

67 9L/PPL-0017 Ley de Memoria histórica de Canarias y de reconocimiento y reparación moral de las víctimas canarias de la Guerra Civil y la dictadura franquista, publicado en el Boletín Oficial del Parlamento de Canarias, número 529, 7 de diciembre de 2018.

68 Cabrera Acosta, Rivero Cabeza, 2013.

${ }^{69}$ Heredero Gascueña, León Álvarez, 2012 y 2014; Heredero Gascueña, León Álvarez, Studer Villazán, 2012. 
que tuvo vigencia hasta 2012. El trabajo hecho puede recuperarse de la página web del proyecto, donde también se especifican todas las publicaciones científicas y divulgativas realizadas..$^{70}$ Asimismo, se intuye que los trabajos en esta línea de investigación se mantienen activos desde los grupos Hispona o HISTAGRA ${ }^{71}$, en los que continúan trabajando sobre este tema Antonio Míguez Macho ${ }^{72}$ o profesores como Emilio Grandío, María Jesús Souto o Lourenzo Fernández Prieto, entre otros.

En Asturias también se constata que el empuje de la profesora María del Carmen García García, desde el Departamento de Historia de la Universidad de Oviedo, se ha materializado en las investigaciones necesarias para localizar y ubicar las fosas comunes existentes en el Principado, tarea que se llevó a término a partir de tres proyectos de investigación financiados por el gobierno autonómico y en los que también participó otro profesor, Rubén Vega. ${ }^{73}$ Los resultados de la colaboración entre la universidad y las instituciones se pueden verificar en la red, y en 2017 el gobierno asturiano anunció una actualización del mapa, así como nuevas subvenciones para asociaciones y familiares de represaliados. ${ }^{74}$ Por el contrario, los resultados no están tan definidos a nivel de publicaciones científicas: en este caso se intuye que se priorizó el trabajo de investigación para aportar información y análisis a la sociedad. ${ }^{75}$

En el País Vasco y Navarra, las universidades se han interesado por el tema básicamente desde la antropología física. Desde el ámbito de la historia, el Instituto de Historia Social Valentín de Foronda, dependiente

70 Nomes e Voces, <http://www.nomesevoces.net/gl/>.

71 Hispona (Historia Política y de los Nacionalismos), <http://hispona.org/>; HISTAGRA (Historia Agraria e Política do Mundo Rural, Séculos XIX y XX), de la USC (Universidad de Santiago de Compostela), <http://histagra.usc.es/>.

72 Míguez Macho, 2009 y 2014.

73 En el mapa interactivo de las fosas, publicado en <http://tematico.asturias.es/asunsoci/fosas/index.htm>, es posible apreciar los resultados de la investigación.

${ }^{74}$ La Vanguardia, «Asturias actualizará el mapa de fosas de la guerra civil», 26 de enero de 2017, <http://www.lavanguardia.com/vida/20170126/413719280769/asturias-actualizara-el-mapa-de-las-fosas-comunes.html>.

75 Es destacable el hecho de que, a parte de algunas publicaciones y participaciones en congresos, no se ha localizado ningún monográfico o artículo en alguna revista científica explicando la gran tarea de investigación desarrollada. Asimismo, se quiere destacar que personas vinculadas al proyecto - Claudia Cabrero Blanco, Pedro Luis Alonso García o Irene Díaz Martínez - han realizado tesis doctorales relacionadas con la represión franquista o han participado en libros colectivos que tienen vinculación con la materia, a pesar de que la cuestión de las fosas no tenga centralidad en sus investigaciones. 
de la Universidad del País Vasco, está realizando diversas investigaciones históricas centradas en la violencia política y la represión, en las que, hasta el momento, las exhumaciones no tienen un papel destacado, mientras que desde la Universidad de Navarra, los profesores Emilio Majuelo y Fernando Mendiola, dos individualidades más, llevaron a término un estudio interdisciplinar, encargado por el Parlamento Foral de Navarra, que entregaron en diciembre de 2014, y en el que indicaban la provisionalidad de la investigación y al que sumaban los datos existentes y correspondientes a las fosas comunes. ${ }^{76}$

En estas regiones es indispensable ubicar en el vértice de los docentes implicados en el análisis de la violencia a través de las exhumaciones al doctor Francisco Etxeberria, que ha trabajado sobre todo desde la Sociedad de Ciencias Aranzadi. Esta institución ha firmado convenios temporales con los gobiernos vasco y navarro para realizar diferentes investigaciones relacionadas con la guerra civil y el franquismo, y entre ellas está la localización y exhumación de fosas, realizando una tarea que implica siempre una perspectiva global: investigación histórica con uso de fuentes archivísticas y orales; localización de la fosa y exhumación. Etxeberria y el equipo de Aranzadi han publicado numerosos artículos en revistas indexadas, pero obviamente en otro ámbito de las ciencias. El trabajo desarrollado por la Sociedad de Ciencias Aranzadi es impresionante y, en la actualidad, al haberse implicado en la primera exhumación del siglo XXI y tener apoyo económico institucional, custodia el mayor fondo documental respecto a las fosas de la guerra civil del País Vasco y de toda España. ${ }^{77}$ Solo puede hacerse una lectura positiva de este hecho, frente a la displicencia de los distintos gobiernos estatales, que en ningún momento han parecido tener la voluntad de crear un fondo específico al respecto, máxime cuando el mismo doctor Etxeberria calcula que entre 2000 y 2016 se exhumaron 8.500 esqueletos de unas 350 fosas, que, según su parecer, se corresponde con tan sólo un diez por ciento de las fosas existentes en España. ${ }^{78}$

${ }^{76}$ Los resultados de este estudio se pueden consultar en <http://www.todoslosnombres.org/sites/default/files/tln_doc_fdmhn_memoria_actividades_2014.pdf>.

77 En la página web que el Gobierno vasco ha dedicado a la memoria histórica se especifica la normativa relacionada, <http://www.euskadi.eus/gobierno-vasco/politica-memoria-historica/>.

${ }^{78} \mathrm{La}$ entrevista al antropólogo forense Etxeberria se puede consultar en <http://www. elmundo.es/pais-vasco/2016/02/28/56d325faca474142738b458c.html>. 
En Andalucía, la sociedad ha empujado a la acción política y las universidades han participado en la producción historiográfica. ${ }^{79} \mathrm{~A}$ pesar de que no fue hasta 2017 cuando se aprobó una ley propia, no han dejado de hacerse diversas actuaciones, como la creación del Comisariado de la Memoria Histórica, que luego pasó a convertirse en la Dirección General de Memoria Democrática. ${ }^{80}$ Las universidades andaluzas, desde los departamentos o áreas de historia contemporánea, han tenido un papel crucial respecto la producción historiográfica, pero en la que la cuestión de las fosas no ha adquirido un papel prominente. Se han hecho investigaciones centradas en la represión económica a través del estudio de los Tribunales de Responsabilidades Políticas, los procesos de depuración, la represión a la masonería, el exilio... ${ }^{81}$ Pero a nivel de estudios respecto a las fosas, las universidades validaron - sin participar de manera oficial - el resultado de los mapas de fosas publicados. A pesar de se han publicado algunas tesis doctorales sobre el tema, ${ }^{82}$ aún no existe una producción académica en la que se tengan en cuenta los datos que aportan las fosas y las exhumaciones, aunque confiamos en que con las actuaciones que se están llevando a cabo no van a tardar en publicarse..$^{83}$

A parte del trabajo realizado desde las universidades, es imprescindible destacar toda la labor desarrollada por las muy diversas asociaciones de familiares, estudiosos, sindicatos... Una tarea de investigación y divulgativa que todo parece indicar que será difícil de mantener con los cambios políticos que se están produciendo en estos primeros meses de 2019, cuando PP, Ciudadanos y Vox han anunciado su alianza para gobernar en Andalucía, asegurando quieren eliminar la legislación memorialística de la comunidad. ${ }^{84}$ Una página web de obligada consulta, pues se ha

79 Del Río Sánchez, 2005.

${ }^{80}$ Ley 2/2017, de 28 de marzo, de Memoria Histórica y Democrática de Andalucía, BOJA núm. 63, 23 de abril de 2017.

${ }^{81}$ Conferencia de Leandro Álvarez Rey (Universidad de Sevilla), en la Universitat de València, en el marco de la «Jornada Memoria histórica: los límites y las posibilidades de la ley», 15 de abril de 2016. En ella se explica detalladamente los ámbitos en los que las universidades andaluzas han estado trabajando respecto a la guerra civil y la dictadura franquista. Se puede visionar la conferencia en $<\mathrm{https}$ ://www.youtube.com/watch?v=0J0r6FPm5h8>.

82 Hernández Burgos, 2012; Giráldez Díaz, 2014; Guerrero Moreno, 2015.

83 Son públicos muchos de los informes de actuaciones, que la Junta de Andalucía publica en su web, así como las memorias anuales desde 2015 a 2017; Baquero, 2015 y 2018. Destaca la reciente publicación de Barranquero Texeira y Prieto Borrego, 2018.

${ }^{84}$ Juan Miguel Baquero, «PP, Ciudadanos y Vox liquidan la ley de Memoria Histórica de Andalucía para convertirla en una "ley de concordia"», eldiario.es, 9 de 
ido convirtiendo en otra gran base de datos sobre todo lo que se refiere a la recuperación de la memoria histórica en Andalucía, es la de Todos los nombres ${ }^{85}$ Esta se ha convertido en un repositorio impresionante de documentos de todo tipo, y que ha sumado a su función original la de archivo virtual. Es evidente que no es la única, hay más de setenta asociaciones de memoria en la comunidad andaluza, pero es imprescindible citarla incluso a nivel estatal.

En las comunidades de Castilla y León, Castilla-La Mancha o la Rioja no se ha producido una implicación institucional estatal o comunitaria y, por consiguiente, sin aportación económica alguna en este sentido hasta hace muy poco tiempo. Por el momento, ha sido básicamente la sociedad civil, articulada alrededor de asociaciones muy diversas, la que ha incentivado y desarrollado investigaciones centradas en documentar y exhumar fosas comunes. Es necesario esperar para poder analizar la repercusión que tendrá la normativa aprobada en Castilla y León ${ }^{86}$, así como la intención de actuar anunciada por la Administración riojana. ${ }^{87}$ Las investigaciones universitarias que se han llevado a término se ha realizado a través de los grupos I + D, dependientes del Ministerio de Economía, Industria y Competitividad, o bien aprovechando las subvenciones del Ministerio de Presidencia de los años 2010 y 2011, a las que las universidades pudieron acceder.

En la Universidad de Burgos, el profesor Ignacio Fernández de Mata es quien más ha estudiado el eje represivo que constituyen las fosas y que unen con un hilo invisible el siglo XX con el XXI en el aspecto político. Al respecto ha dirigido diversas investigaciones ${ }^{88}$ y, en 2016 , leyó su segunda tesis doctoral, centrada en los desaparecidos de la guerra. ${ }^{89}$

enero de 2019, <https://www.eldiario.es/andalucia/PP-Ciudadanos-Memoria-HistoricaAndalucia_0_855315332.html >.

${ }^{85}$ Desde sus inicios y hasta 2011, el proyecto estuvo coordinado por Francisco Espinosa Maestre, <http://www.todoslosnombres.org/>.

86 DECRETO 9/2018, de 12 de abril, de la Memoria Histórica y Democrática de Castilla y León, Boletín Oficial de Castilla y León, 16 de abril de 2018.

87 El 12 de mayo de 2017 se aprobó la creación del Consejo Asesor de la Memoria Histórica, <https://www larioja.org/comunicacion/es/noticias/aprobado-decreto-creacionconsejo-asesor-memoria-historica>.

88 Por ejemplo, en 2010-2011 «La represión durante la Guerra Civil y el Franquismo en la capital de la Cruzada. Conocimiento y análisis de las experiencias traumáticas, de explotación y subalternidad, y lugares de la memoria de Burgos» o la dirección actual del grupo Sociedad y Conflicto. Estudios culturales de las violencias.

89 Fernández de Mata, 2016. 
Es importante señalar que aunque los trabajos lógicamente incluían aspectos de investigación histórica, el impulso y la dirección han sido llevadas a cabo por un antropólogo. Y esta cuestión es otra de las que se deben destacar en este ámbito de análisis, puesto que, en las otras universidades de la comunidad donde se han realizado investigaciones relacionadas con las fosas, la presencia de antropólogos sociales también ha sido destacada.$^{90}$ Es el caso del estudio sobre el tema en Ciudad Real, donde se está trabajando desde hace años para poner nombre a los desaparecidos de la región y numerar las fosas comunes existentes, que ya pueden consultarse en la red, y en el que la Diputación ha participado económicamente, un hecho a destacar. ${ }^{91}$ El estudio ha sido dirigido por Manuel Ortiz Heras, doctor en Historia de la Universidad de Castilla-La Mancha, con la colaboración de otros investigadores y del antropólogo de la UNED Julián López.

También de la UNED es la profesora Paloma Aguilar, quien, desde el Departamento de Ciencia Política y de la Administración, en los últimos años ha focalizado parte de sus análisis en las fosas comunes de la guerra civil que se exhumaron durante la Transición..$^{92}$ Sus investigaciones están ayudando a llenar un vacío historiográfico que, al parecer, no estaba tan desierto como se creía; aparte de las fosas navarras que Aguilar estudia, se está descubriendo que durante los años ochenta y noventa del siglo pasado nunca se dejaron de abrir fosas por parte de aquellos familiares que pretendían recuperar los restos óseos de los que consideraban «sus muertos»..$^{93}$

Asimismo, es antropólogo el investigador principal del grupo que centraliza las investigaciones más importantes respecto a las fosas comunes de la guerra civil y su herencia en el presente: esas huellas que constituyen los huesos exhumados. Desde 2010, el número de investigadores que se agrupan en el equipo de Las políticas de la memoria, con sede en el CSIC, en Madrid, no ha parado de crecer y de internacionalizarse. Francisco Ferrándiz ha encadenado la coordinación de tres pro-

90 Exceptuando los trabajos de Juan Montero, véase la bibliografía.

91 Proyecto Víctimas de la Dictadura, realizado con financiación de procedencias diversas durante los años 2014-2018: La Junta de Comunidades de Castilla-La Mancha y el proyecto de $\mathrm{I}+\mathrm{d}+\mathrm{i}$ para jóvenes investigadores impulsados por la Diputación Provincial de Albacete y la UCLM. <http://www.victimasdeladictadura.es/>.

92 Aguilar, 2018 y 2019.

93 Ferrándiz, Aguilar, 2016; De Kerangat, 2017. 
yectos consecutivos de I + D, y la producción científica de la asociación es constante. Resulta imposible detallarla de manera exhaustiva, puesto que a los artículos de gran impacto científico internacional deben sumársele los libros, los congresos, los seminarios, las conferencias y la participación continua de sus miembros en eventos nacionales e internacionales. Es preferible y recomendable consultar su extensa y cuidada página web. ${ }^{94}$ Obviamente, destacan las publicaciones de Ferrándiz, pero también sobresalen las tesis doctorales que se han realizado bajo el cobijo del grupo, así como como la capacidad del proyecto para asimilar y sumar jóvenes doctores que en la actualidad participan en las investigaciones del equipo. ${ }^{95} \mathrm{Y}$ dentro de este análisis global que realiza Las políticas de la memoria, destacan dos cuestiones básicas: la interdisciplinariedad y la perspectiva comparada en que se sustentan sus investigaciones. Son o han sido antropólogos, pero también profesionales de la literatura, la historia, las ciencias políticas, las ciencias forenses, arqueólogos, biólogos, periodistas, psicólogos, cineastas y fotógrafos.

Al mismo tiempo, la internacionalización que ha desarrollado el proyecto permite asegurar la ambición de no aislar el caso español, y así poder comprobar sus semejanzas con otros procesos europeos o del resto del mundo, donde los conflictos bélicos han comportado asimismo la existencia de desaparecidos, fosas comunes y exhumaciones, verificando que también en España se ha dado, por ejemplo, lo que se conoce como el «giro forense». Con la implementación de este método, las exhumaciones han contado con la extensa participación de patólogos y antropólogos forenses para ocuparse de los restos humanos, lo que ha significado su implicación en la creación del relato respecto al pasado, a la vez que su papel se ha normalizado, tanto aquí como en muchos otros países. ${ }^{96}$ Se demuestra que el caso español y las fosas que perviven en su territorio, por lo tanto, no son ninguna excepcionalidad.

En Aragón y Cataluña, las universidades han tenido una escasa participación directa en los proyectos de investigación relacionados con las fosas, pues en ambas comunidades las respectivas administraciones asumieron desde el principio la cuestión de la memoria histórica como un interés institucional.

\footnotetext{
${ }_{94}$ Disponible en <http://www.politicasdelamemoria.org/>.

95 Hristova, 2016; Douglas, 2017; Aragüete-Toribio, 2015.

${ }^{96}$ Garibian, Anstett, Dreyfus, 2017.
} 
En Aragón se creó el programa Amarga Memoria (2004-2012), y en Cataluña se acabó creando el Memorial Democràtic, que supuso una continuidad con las políticas de memoria iniciadas en $2003 .{ }^{97} \mathrm{La}$ Universidad de Zaragoza hacía ya tiempo que estudiaba la violencia política a pesar de que no participó, por ejemplo, en la elaboración del mapa de fosas ni en las exhumaciones. ${ }^{98}$ Lo mismo sucedió en Cataluña, pese a que la Universitat Autònoma de Barcelona se involucró en dos exhumaciones que tenían que servir como pruebas piloto para una reglamentación posterior. ${ }^{99}$ De esta forma, la implicación se realizó desde la antropología física, con Assumpció Malgosa como una las académicas que en el caso catalán siempre ha estado comprometida en las exhumaciones y posteriores identificaciones genéticas, y con Queralt Solé, profesora del Departamento de Historia y Arqueología de la Universitat de Barcelona. ${ }^{100}$ Esta última ha hecho del análisis de las fosas comunes desde una perspectiva histórica una de sus líneas de investigación principal desde que leyó su tesis en 2008. ${ }^{101}$ Finalmente, en Cataluña y por encargo de la Generalitat, el profesor Josep Sánchez Cervelló, de la Universitat Rovira i Virgili de Tarragona, también ha investigado la localización de fosas, así como sobresale el trabajo realizado desde la Universitat de Lleida, desde la que la profesora Conxita Mir ha liderado un pormenorizado estudio de la represión franquista, los lugares de memoria y las fosas existentes en la provincia, resaltando las actuaciones que en ellas se han llevado a cabo con especial atención a la del cementerio de Lleida. Sin embargo, más allá de los estudios citados, no ha existido una colaboración continua entre las universidades y las administraciones.

97 Aragón: Disponible en <http://www.patrimonioculturaldearagon.es/amarga-memoria>. El Memorial Democràtic se creó por ley (Lley 13/2007, de 31 de octubre), y se definía como «una institución pública que tiene como finalidad la recuperación, conmemoración y fomento de la memoria democrática durante el periodo entre 1931 y 1980».

98 El Departamento de Historia Moderna y Contemporánea de la Universidad de Zaragoza ha ido encadenando diversos proyectos de investigación centrados en cuestiones políticas y violencia del siglo $\mathrm{xx}, \mathrm{y}$ asimismo tiene grupos de estudio consolidados que investigan y analizan en ese ámbito, cuyos investigadores principales son Julián Casanova, Carlos Forcadell, Miguel Ángel Ruiz Carnicer o Ángela Cenarro.

99 Ley 10/2009, de 30 de junio, sobre la localización y la identificación de las personas desaparecidas durante la Guerra Civil y la dictadura franquista. Véase Solé, 2016.

100 Malgosa, et al., 2010. Ambas forman parte del comité asesor que estipula la Ley 10/2009 citada, y fueron las comisarias de la exposición «Fosses comunes: un passat no oblidat», en mayo de 2010.

101 Solé, 2008. 
Finalmente, en las islas Baleares la implicación académica ha sido poco destacable hasta que, en 2016, se aprobó una ley para actuar en las fosas y hacer políticas públicas de memoria. ${ }^{102}$ Similar al proceso desarrollado en Zaragoza, desde el Departament de Ciències Històriques i Teoria de les Arts de la UIB se ha trabajado temas de violencia política, represión social y el franquismo, aunque no ha existido una relación estrecha entre la universidad y la institución. ${ }^{103}$

A pesar de ello, la ley aprobada en 2016 sí incluyó la participación de la universidad en una comisión técnica que deberá participar en la elaboración de un censo de desaparecidos y un mapa de fosas comunes, que a buen seguro recogerá los trabajos realizados previamente por las asociaciones, auténticas protagonistas en las islas de la mayoría de las investigaciones realizadas, y de aquellos resultados que se han conseguido finalmente a través de la implicación institucional. ${ }^{104}$

Esta panorámica general muestra una relación muy desigual entre la universidad y todo lo que rodea las fosas comunes de la guerra civil. Además, para añadir más elementos a esta reflexión, debemos tener en cuenta que en estas líneas no se ha tratado la literatura académica que se está publicando fuera de España: doctorandos de diversas especialidades que han leído tesis, y profesores de muchos países que han reflexionado sobre las fosas y las exhumaciones desde diversos enfoques. Una bibliografía muy extensa que, como tantas otras cosas, merecería un artículo exhaustivo.

\section{Elementos para la reflexión}

Es innumerable la historiografía realizada de la represión franquista, unos estudios que en su inmensa mayoría se empezaron a desarrollar y publicar a mediados de los años ochenta del siglo Xx, con implicación de jóvenes investigadores aún no asentados en el mundo académico, que fi-

102 Llei 10/2016, de 13 de juny, per a la recuperació de persones desaparegudes durant la Guerra Civil i el franquisme.

${ }_{103}$ Básicamente las investigaciones de David Ginard o las tesis dirigidas por Sebastià Serra, entre otras, la de Garí Salleras, 2017.

${ }^{104}$ Existen unos mapas previos, realizados por las asociaciones Memòria de Mallorca i Fòrum per la Memòria d'Eivissa i Formentera, concretamente en Suárez Salvà (coord.), 2011 y 2012; Fòrum per la Memòria d'Eivissa i Formentera, 2015. 
nalmente fue asumiendo ese interés hasta desarrollarse o incentivarse desde los departamentos de historia contemporánea correspondientes. Se pasó de investigar a partir de «fuentes colaterales» a poder analizar los documentos preservados en archivos militares o judiciales.

Afortunadamente no se ha dejado de avanzar e investigar, y cada vez es más conocido el universo represivo franquista. En el siglo XXI, para esos estudios resulta imprescindible tener en cuenta una nueva fuente que años atrás era inconcebible. Los datos que contienen las fosas y sus exhumaciones se demuestran esenciales para los familiares y para la defensa de los derechos humanos, como también lo son para poder reconstruir los procesos represivos practicados por los victimarios. Hasta ahora, a partir de la documentación estudiada se disponía de información tan crucial como nombres, lugares y cifras, así como las fuentes de memoria oral, y los análisis a partir de estos datos resultan indispensables. Pero ahora, además, puede conocerse por ejemplo, y entre muchos otros aspectos, el grado de violencia practicado sobre los cuerpos antes de ser asesinados; los materiales usados para atar las manos de los que iban a ser ejecutados; la pretensión de los ejecutores de practicar un doble o triple castigo a la víctima y a sus familiares; la voluntad de hacer desaparecer los cuerpos y, a la vez, evidenciar el asesinato quemándolos a pocos kilómetros del pueblo de origen de las víctimas...

Como puede observarse, a pesar de las centenares de fosas excavadas y los miles de cuerpos exhumados en los últimos dieciocho años, así como de cierta aproximación a esos procesos y sus resultados, desde la historia académica el acercamiento a esta nueva fuente ha sido tímido. Básicamente, tres han constituido las formas en las que las universidades han participado: a partir del interés particular de algún profesor; por convenios establecidos con las administraciones de la comunidad autónoma correspondiente; o bien a través de proyectos de investigación. En este sentido destaca el hecho de que no fueron muchas las propuestas universitarias que se presentaron a las subvenciones de Presidencia del Estado cuando fue posible hacerlo. En el año 2010, de 188 solicitudes de subvención, 13 provenían de universidades y, de estas, 5 estaban relacionadas con aportar luz respecto a los desaparecidos y la existencia de fosas comunes. En 2011 se otorgaron 190 subvenciones y en esta ocasión fueron 27 las universidades que se presentaron, el doble que el año anterior, y 4 los proyectos que se relacionaban de alguna manera con las fosas de la guerra civil. Parece evidente que, como en muchas otras cuestiones, el hecho de disponer o no de recursos económicos 
condiciona las investigaciones que se pueden llevar a cabo. Sin embargo, también parece evidente que, aunque haya posibilidades económicas que no sean subvenciones, lo que diferencia que una u otra universidad haya participado en esta línea de investigación que reconoce la fosa común de la guerra civil como unidad de análisis es el interés y la voluntad particular de algunos profesores, así como los objetivos de las administraciones. Algunas de estas han preferido trasladar a las universidades el peso de la investigación y el análisis de un convulso siglo Xx; otras no han querido participar en nada ni de ninguna manera, y algunas otras han asumido la cuestión por completo, excluyendo, justamente, la universidad.

Con respecto a la cuestión económica, no solo ha resultado básica para la investigación y el análisis académicos, sino que también ha sido fundamental para las actuaciones que pretendieran realizarse desde cualquier ámbito de la sociedad civil. De hecho, la repercusión que tiene la realidad política sobre toda la cuestión de la «memoria histórica», entendida como un movimiento reivindicativo y, a la vez, como un proceso abierto de investigación del pasado, es indudable y merecería un análisis profundo. La posibilidad de tener o no financiación aportada por las instituciones públicas implica que se realicen, o no, investigaciones. En ese sentido, el Estado otorgó las últimas subvenciones, a las que también se podían presentar las universidades, durante el año 2011. También en las diferentes producciones culturales y científicas se observa un antes y un después de 2012, cuando el Estado dejó de aportar ayudas económicas para la realización de estudios al respecto.

En los últimos años, comunidades autónomas que no habían establecido ninguna política respecto a las fosas comunes o la memoria histórica en general, han empezado a aprobar normativas diversas. En ese sentido, en Mallorca y en Valencia es posible observar ya ese cambio que ha permitido exhumar fosas, al subvencionar actuaciones muy diversas en las que también las universidades se han implicado. De hecho, se advierte que cuando existe un convenio provechoso y un acuerdo firme entre la administración y la academia, las actuaciones conjuntas contribuyen con resultados de investigación muy potentes. En otros territorios solo el tiempo dirá si la existencia de estas normativas es un revulsivo o un freno para un estudio posterior y para la dignificación y la apertura de fosas comunes, así como para su análisis desde una perspectiva histórica.

La interdisciplinariedad es otra cuestión que se observa como una pauta en aumento. Mientras los historiadores se han acercado con timidez, 
profesionales de otros ámbitos científicos han mostrado un mayor interés, ya sea desde la antropología social, la arqueología o la antropología forense como ejemplos más destacados. Es posible que la metodología y la proximidad temporal guarden alguna relación con ello.

Comprender las fosas comunes como una unidad de análisis y aceptar los resultados de las exhumaciones como otra fuente de estudio, pasa por un necesario trabajo de campo, inseparable del trabajo en los archivos. A pesar de que la memoria oral está absolutamente aceptada y asentada en la historiografía española, los historiadores tienden a focalizar sus análisis en documentos diversos o en bibliografía, y la biblioteca y el archivo se convierten en su espacio de trabajo habitual. Por el contrario, y en relación con las fosas, es inevitable el trabajo de campo y tratar con los familiares de las víctimas, sobre un tema que contiene un componente actual además del histórico. De hecho, las fosas comunes de la guerra civil unen con un hilo invisible el siglo XX político español con el siglo XXI. El campo y la actualidad, un espacio físico y otro temporal en el que los antropólogos, por citar un ejemplo, acostumbran a moverse con más naturalidad que los historiadores.

Con toda la producción cultural existente y con la nueva e increíble fuente histórica que constituyen las fosas, así como todos los aportes que las rodean, consideramos que el momento de compilar su historia está más cerca que lejos. En un mundo en el que tiempo se ha acelerado, es posible adquirir cierta perspectiva temporal para analizar tantas cosas... sin duda de forma interdisciplinar. Historia cultural, historia social, historia oral, historia comparativa, microhistoria... Desde una perspectiva de base histórica, son muchas las preguntas y las posibilidades de análisis. Vamos a empezar a responderlas y a estudiar esa mezcla de pasado reciente y presente, que, para mucha gente, aún resulta doloroso.

\section{Bibliografía}

Aguilar FernándeZ, P., «El primer ciclo de exhumaciones y homenajes a fusilados republicanos en Navarra», Kamchatka. Revista de análisis cultural, n. $.^{\circ} 13,2019$.

AgUilar FERNÁNDEZ, P., «La evocación de la guerra y del franquismo en la política, la cultura y la sociedad españolas», JuLIÁ, S. (Ed.), Memoria de la guerra y del franquismo, Taurus, Barcelona, 2006, pp. 285-306. 
Aguilar Fernández, P., «Los lugares de memoria de la guerra civil. El Valle de los Caídos: la ambigüedad calculada», en Tusell, J. (Coord.), El régimen de Franco (1936-1975). Política y relaciones exteriores, UNED, Madrid, 1993.

Aguilar FernáNDEZ, P., «Memoria y transición en España. Exhumaciones de fusilados republicanos y homenajes en su honor», Historia y Política, n. 39 , 2018, pp. 291-325. DOI: <https://doi.org/10.18042/hp.39.11>.

Amo SÁnchEZ, A., «Dramaturgias de lo imprescriptible: un teatro para la recuperación de la memoria histórica en España (1990-2012)», Anales de la Literatura Española Contemporánea / Annals of Contemporary Spanish Literature, n. ${ }^{\circ} 39: 2,2014$, pp. 39-67.

Amo SÁnchez, A., «El teatro de la recuperación de la memoria histórica en España: zanjar el pasado abriendo las zanjas», Cuadernos de Dramaturgia Contemporánea, n. ${ }^{\circ}$ 17, 2012, pp. 57-71.

Aragüete-Toribio, Z., Producing History in Spanish Civil War Exhumations. From the Archive to the Grave, Palgrave Macmillan, Londres, 2017.

Armengou, M., Belis, R., Las fosas del silencio: ¿hay un holocausto español?, Plaza \& Janés, Televisió de Catalunya, Barcelona, 2004.

BAquero, J. M., Que fuera mi tierra, Anuario 2015. Intervenciones en fosas comunes del franquismo en Andalucía, Sevilla, eXtra Comunicación, 2016.

BÁRCENA, A., «Redención de penas en el Valle de los Caídos: las fuentes rebaten el mito», Aportes. Revista de historia contemporánea, Vol. 79, 2012, pp. 5-29.

Barranquero Texeira, E., Prieto Borrego, L, La derrota bajo tierra. Las fosas comunes del franquismo. Granada, Comares, 2018.

Bernard, C., Desvelados, Pamplona, Alkibla Editorial, 2010.

BotTois, O., «La mémoire historique de la guerre civile espagnole et du franquisme dans l'art contemporain espagnol: la pratique de l'art, l'écriture de l'histoire», en Llombart-Huesca, M., Thibaudeau, P., «Politiques, récits et représentations de la mémoire en Espagne et en Amérique Latine aux Xxe et XXIe siècles», Pandora, n. ${ }^{\circ}$ 12, 2014.

Breu, R., Tractar la memòria a l'aula a través del cinema, Generalitat de Catalunya, Barcelona, 2015.

CABrera Acosta, M. A., La represión franquista en el Hierro, LeCanarien Ediciones, Santa Cruz de Tenerife, 2015 (1. a ed. Tagoror De Ediciones, Fuerteventura, 1985).

Cabrera Acosta, M. A., Rivero Cabeza, P. (Coord.), Luces sobre un tiempo en gris: Exposición bibliográfica sobre la represión franquista en Canarias, Servicio de Publicaciones Universidad de La Laguna, La Laguna, 2013.

CAparrós, J. M. a, Crusells, M., SÁnChez Barba, F. (Eds.), Memoria histórica y cine documental, Edicions UB, Barcelona, 2016. 
CARballés, J. A., «Los «niños de la guerra» o las huellas del exilio infantil en el espacio público», Historia Social, n. $.76,2013$, pp. 107-124.

Cavallé, J., Peus descalços sota la lluna d'agost, Arola Editors, Tarragona, 2009.

Cercas, J., Soldados de Salamina, Tusquets, Barcelona 2001.

Chaves Palacios, J., et al., Proyecto de recuperación de la Memoria Histórica en Extremadura: balance de una década (2003-2013), PREMEX, 2014.

ChAVEs RodríGuez, C., Justicia militar y consejos de guerra en la Guerra Civil y franquismo en Badajoz: delitos, sentencias y condenas a desafectos, Universidad de Extremadura, 2014.

Colmeiro, J. F., Memoria histórica e identidad cultural. De la posguerra a la postmonernidad, Barcelona, Anthropos, 2005.

CONESA, R., «Del duelo clandestino al recuerdo colectivo: el Fossar de la Pedrera del cementerio de Montjuïc», en Mir Curcó, C., Gelonch Solé, J. (Eds.), Duelo y memoria. Espacios para el recuerdo de las víctimas de la represión franquista en perspectiva comparada, Edicions de la Universitat de Lleida, Lleida, 2013, pp. 171-198.

CORBALÁN, A., «Reconstrucción del pasado histórico: nostalgia reflexiva en Cuéntame cómo pasó», Journal of Spanish Cultural Studies, n. ${ }^{\circ}$ 10, 2009, pp. 341-357.

Crumbaugh, J., «Afterlife and Bare Life: The Valley of the Fallen as a Paradigm of Government», Journal of Spanish Cultural Studies, Vol. 12:4, 2011, pp. 419-438.

CUÑADO, I., «Despertar tras la amnesia: guerra civil y postmemoria en la novela española del siglo XXI», Dissidences: Hispanic Journal of Theory and Criticism, Vol. 2:Iss. 3, 2007, pp.1-11, <https://digitalcommons.bowdoin.edu/ cgi/viewcontent. cgi ?article $=1058 \&$ context $=$ dissidences $>$.

De Kerangat, Z., «Beyond Local Memories: Exhumations of Francoism's Victims as Counter-discourse during the Spanish Transition to Democracy», en SindBæK, T., Tornquist-Plewa, B. (Eds.), The Twentieth Century in European Memory. Transcultural Mediation and Reception, Brill, Boston, 2017.

De la Rubia Barbón, A., De la Rubia Huete, P., La fosa de Valdediós, Fundación Municipal de Cultura, Educación y Universidad Popular del Ayuntamiento de Gijón, 2006.

Del Río SÁnchez, A., «Los alcances del movimiento social de Recuperación de la Memoria Histórica. Apuntes de la experiencia andaluza», en VALCUENDE, J. M., NAROTZKY, S., Las políticas de la memoria en los sistemas democráticos: poder, cultura y mercado, Fundación El Monte, Asociación Andaluza de Antropología y Federación de Asociaciones de Antropología del Estado Español, Sevilla, 2005, pp.133-154.

Douglas, L., Producing Historical Knowledge in a World of Absence: Forensic Science, Cultures of Documentation, and the Politics of Memory in PostFranco Spain, New York University, Nueva York, 2017. 
Dumousseau Lesquer, M., «De la révélation à la mise en garde: quand les artistes espagnols contemporains retrouvent la mémoire historique», en LLOMBart-Huesca, M., Thibaudeau, P., «Politiques, récits et représentations de la mémoire en Espagne et en Amérique Latine aux XXe et XXIe siècles», Pandora, n. ${ }^{\circ}$ 12, París, 2014.

Espinosa, F. (Ed.), Violencia roja y azul: España, 1936-1950, Crítica, Barcelona, 2010.

EtXeberria, F., Pla, K. (Dir.), El Fuerte de San Cristóbal en la memoria: de prisión a sanatorio penitenciario: El cementerio de las botellas, Pamiela, Pamplona 2014.

FABER, S., «La literatura como acto afiliativo: la nueva novela de la Guerra Civil (2000-2007)», en Álvarez Blanco, M. de P., DorCA, T. (Coord.), Contornos de la narrativa española actual, 2000-2010: un diálogo entre creadores y críticos, Iberoamericana Vervuert, Madrid, 2011, pp. 101-110.

FERnÁNDEZ DE MATA, I., Lloros vueltos puños. El conflicto de los «desaparecidos» y vencidos de la Guerra Civil española, Universidad de Burgos, Editorial Comares, Granada, 2016.

FERRÁndiz, F., El pasado bajo tierra. Exhumaciones contemporáneas de la Guerra Civil, Anthropos, Barcelona, 2014.

FERRÁndiz, F., «Francisco Ferrándiz: "Una fosa común abre un espacio de memoria"», Público, 31 de octubre de 2011, <http://www.publico.es/actuali$\mathrm{dad} /$ francisco-ferrandiz-fosa-comun-abre.html $>$.

FERrÁndiz, P., Aguilar, P., «Memory, media and spectacle: Interviú’s portrayal of Civil War exhumations in the early years of Spanish democracy», Journal of Spanish Cultural Studies, 17:1, 2016, pp.1-25.

FERRERO, J., Las trece rosas, Siruela, Madrid, 2003.

Fonseca, C., Trece rosas rojas, Temas de Hoy, Madrid, 2004.

GARí SALlerAs, T., La repressió a Mallorca en el transcurs de la Guerra Civil (1936-1939): memòria d'una coerció planificada, Universitat de les Illes Balears, 2017.

Garibian, S., Anstett, E., Dreyfus, J. M. (Dir.), Restos humanos e identificación. Violencia de masa, genocidio y el «giro forense», Miño y Dávila Editores, Buenos Aires, 2017.

Gimeno, M., Revolució, guerra i repressió al Pallars, 1936-1939, Abadia de Montserrat, Barcelona, 1987.

Giráldez Díaz, J., Política de la memoria y memoria de la política. Una reflexión sobre la memoria histórica en Andalucía, Universidad de Sevilla, Sevilla, 2014.

GonZÁlez-RuIBAL, A., Volver a las trincheras: Una arqueología de la guerra civil, Alianza Ensayo, Madrid, 2016.

«Guerra y literatura. Actas del XIII Simposio Internacional sobre Narrativa Hispánica Contemporánea», Fundación Luis Goytisolo, Cádiz, 2006. 
Guerrero Moreno, R., Memoria histórica: Una experiencia desde Andalucía, Universidad de Sevilla, Sevilla, 2015.

Gutiérrez Lozano, J. F., SÁnchez Alarcón, M. I., «La memoria colectiva y el pasado reciente en el cine y la televisión. Experiencias en torno a la constitución de una nueva memoria audiovisual sobre la Guerra Civil», Revista HMiC, 2005, pp.151-168.

GuZmán, A., La memoria de la Guerra Civil en el teatro español: 1939-2009, Universidad de Salamanca, Salamanca, 2012.

Hepworth, A., «Site of memory and dismemory: the Valley of the Fallen in Spain», Journal of Genocide Research, Vol. 16:4, 2014, pp. 463-485.

Heredero Gascueña, V., León Álvarez, A., «Fuentes y metodología para el estudio de la represión franquista en Tenerife», «XX Coloquio Internacional de Historia Canario-Americana [2012]», Casa de Colón, Cabildo de Gran Canaria, Las Palmas de Gran Canaria, 2014, pp. 1150-1160.

Heredero Gascueña, V., León Álvarez, A., «La recuperación de la memoria histórica en Tenerife: un estudio multidisciplinar sobre los desaparecidos durante la Guerra Civil Española (1936-1939)», Actas del XIX Congreso Nacional de Arqueología Chilena, Arica, Chile, octubre de 2012, pp. 281-285.

Heredero Gascueña, V., León Álvarez, A., Studer Villazán, L. (Coord.), En Rebeldia: once desaparecidos de La Laguna durante la Guerra Civil en Tenerife, LeCanarien Ediciones, Santa Cruz de Tenerife, 2012.

HERnÁNDEZ Burgos, C., Las bases sociales de la dictadura y las actitudes ciudadanas durante el Régimen de Franco: Granada (1936-1976), Universidad de Granada, Granada, 2012.

HERNÁNDEZ CORCHETE, S., La historia contada en televisión. El documental televisivo de divulgación histórica en España, Barcelona, Gedisa, 2008.

Hristova, M., Reimagining Spain: Transnational Entanglements and Remembrance of the Spanish Civil War since 1989, Maastricht University Research Publications, Maastricht, 2016.

IZQUIERDO, J. M., «La narrativa del nieto del derrotado. Últimas novelas sobre la guerra civil española», «ANPE-Norge. IV Congreso nacional: Un ciclo con la reforma educativa «Kunnskapsløftet». ¿Nuevas perspectivas para el español?», Kristiansand, del 19 al 21 de septiembre de 2012.

Jimeno Jurío, J. M., Mikelarena, F., Sartaguda 1936. El pueblo de las viudas, Pamplona, Pamiela, 2008.

JUNQUERA, N., Valientes. El relato de las víctimas del franquismo y de los que le sobrevivieron, Aguilar, Madrid, 2013.

López, F., Cueto Asín, E., GeOrge, D. (Eds.), Historias de la pequeña pantalla: representaciones históricas en la televisión de la España democrática, Iberoamericana Vervuert, Madrid, 2009. 
MalgosA, A., et al., «La antropología forense al servicio de la justicia y la historia: las fosas de la Guerra Civil», Cuadernos de Medicina Forense, Vol. 16 (1-2), 2010, pp. 1-16.

Malgosa, A., Solé, Q., Fosses comunes: un passat no oblidat, Editorial Afers, Catarroja, 2010. [Catàleg d'exposició.]

Martín Bastos, J., Pérdidas de vidas humanas a consecuencia de las prácticas represivas franquistas en la provincia de Badajoz, (1936-1950), Universidad de Extremadura, 2013.

MARTínez DE Pisón, Ignacio, Enterrar a los muertos, Seix-Barral, Madrid, 2005.

Mateo DíEz, Luis, Fantasmas del invierno, Alfaguara, Madrid, 2004.

MAYORGA, J., El dramaturgo como historiador, Madrid, Postmetropolis Editorial, 2015.

MAYORGA, J., El jardín quemado, Universidad de Murcia, 2008. «Memòria contra l'oblit. Les fosses de la Guerra Civil a Eivissa i Formentera», «Fòrum per la Memòria d'Eivissa i Formentera», Eivissa, 2015.

Míguez MACHO, A., La genealogía genocida del franquismo. Violencia, memoria e impunidad, Abada Editores, Madrid, 2014.

Míguez Macho, A., Xenocidio e represión franquista en Galicia. A violencia de retagarda en Galicia na Guerra Civil, Lóstrego, Santiago de Compostela, 2009.

Montero Gutiérrez, J., VALDivielso GutiérRez, E., «Claves metodológicas en el proceso de exhumación e identificación de los restos humanos de la fosa común de la Guerra Civil española de La Granja (Quintanilla de las Viñas, Burgos): aportes desde una perspectiva bio-arqueológica», Munibe Antropologia-Arkeologia, n. ${ }^{\circ}$ 62, 2011, pp. 479-498.

MonTERo GutiÉRREZ, J., et al., «Aterrados, sacados y (des)enterrados: una mirada arqueológica a los paisajes del terror caliente de 1936 en tierras de Castilla», Revista Otarq, n. ${ }^{\circ}$ 2, 2017, pp. 183-204.

Muñoz Encinar, L., Chaves Palacios, J., «Extremadura: Behind the material traces of Franco's repression», Culture \& History Digital Journal, 3(2):2014, e020, CSIC, DOI: <http://dx.doi.org/10.3989/chdj.2014.020>.

Olmeda, F., El Valle de los Caídos. Una memoria de España, Barcelona, Península, 2009.

PorCAR ORIHUEla, J. L., Un país en gris i negre: memòria històrica i repressió franquista a Castelló, Publicacions de la Universitat Jaume I, Servei de Comunicació i Publicacions, Castelló de la Plana, 2013.

Preston, P., El Holocausto español. Odio y exterminio en la Guerra Civil y después, Debate, Barcelona, 2011.

Pujol Masip, M., «Exhumación y estudio de los restos de Ramon Vila Capdevila en el cementerio de Castellnou de Bages», Ebre'38, Revista Internacional de la Guerra Civil (1936-1939), n. ${ }^{\text {o } 7,2017, ~ p p .195-210 . ~}$ 
Quintana Trias, Ll., Más allá de todo castigo. Del silencio a la reparación, Barcelona, Icaria, 2012.

QUINTANA TRIAS, L1., «Un lloc de memòria desafortunat: el cas del Valle de los Caídos», en Sansano, G., Silenci, oblit i preservació de la memòria democràtica. Una aportació transversal, Universitat d'Alacant, Alacant, 2018.

Ríos FruTOS, L. et al., «Informe osteológico de los 46 esqueletos exhumados en Villamayor de los Montes», Recuperado de internet, <http://www.uam.es/ departamentos/ciencias/biologia/antropologia/html/index.html>

RuEDA LAFFOND, J. C., «¿Reescribiendo la historia? Una panorámica de la ficción histórica televisiva española reciente», Alpha, n. ${ }^{\circ}$ 29, 2008, pp. 85-104.

SÁNCHEZ, G., «Desaparecidos», Barcelona, 2011, <http://www .cccb.org/es/exposiciones/ficha/desaparecidos/35374>.

SAnsano, G., «De fosses i fantasmes. Memòria, trauma i identitat en l'escena catalana actual», Journal of Catalan Studies, University of Cambridge, Universitat Oberta de Catalunya, University of Kent, 2014, pp. 4-22.

Serrulla Rech, F., Antropología forense de la guerra civil española, Universidad de Granada, Granada, 2018.

Serrulla Rech, F., et al., «Preserved brains from the Spanish Civil War mass grave (1936) at La Pedraja 1, Burgos, Spain», Science and Justice, n. ${ }^{\circ}$ 56, 2016, pp. 453-463.

Silva, E., Macías, S., Las fosas de Franco: los republicanos que el dictador dejó en las cunetas, Temas de Hoy, Madrid, 2003.

Solé i Sabaté, J. M., VillarRoya, J., L’Ocupació militar de Catalunya: març 1938-febrer 1939, L'Avenç, Barcelona, 1987.

Solé, Q., Els morts clandestins. Les fosses comunes de la Guerra Civil a Catalunya (1936-1939), Afers, Catarroja-Barcelona, 2008.

SolÉ, Q., «Gobiernos democráticos del Estado español frente la persistencia de la memoria y la historia de las fosas de la guerra civil española. La actuación de la Generalitat en Cataluña (2004-2015)», Munibe Antropologia-Arkeologia, n. ${ }^{\circ}$ 67, 2016, pp. 199-214.

SolÉ, Q., «The valley of the fallen: a new El Escorial for Spain», Human Remains and Violence, Vol. 3, n. ${ }^{\circ}$ 1, 2017, pp. 3-21.

Stockey, G., Valley of the Fallen. The (N)ever Changing Face of General Franco's Monument, Critical, Cultural and Communications Press, Nottingham, 2013.

SuÁrez SAlvà, M. (Coord.), Les fosses de la repressió a Mallorca. Mapa de fosses comunes de Mallorca (1. ${ }^{a}$ part), Conselleria d'Afers Socials (Govern Balear) i Associació Memòria de Mallorca, Palma de Mallorca, 2011.

SuÁRez SAlvÀ, M. (Coord.), Mapa de les Fosses comunes de Mallorca (2. ${ }^{a}$ part), Conselleria d'Afers Socials (Govern Balear) i Associació Memòria de Mallorca, 2012, estudio inédito. 
Sueiro, D., El Valle de los Caídos. Los secretos de la cripta franquista, Barcelona, Sedmay Ediciones, Barcelona, 1976 [2. ${ }^{a}$ y 3. ${ }^{\mathrm{a}}$ eds. de Argos Vergara, Barcelona, 1976, 1983].

Torres, F., Oscura es la habitación donde dormimos, Actar, Barcelona, 2007.

TORRES, R., Desaparecidos de la guerra de España (1936-?), Madrid, La Esfera de los Libros, 2002.

TRAPIELlO, A., Las armas y las letras: literatura y guerra civil (1936-1939), Destino, Barcelona, 2010.

Viudas de los Defensores de la República y del Frente Popular de AstuRIAS, Represión de los tribunales militares franquistas en Oviedo. Fosa común del cementerio civil de Oviedo, Oviedo, 1988.

WINTER, U., «De la memoria recuperada a la memoria performativa. Hacia una nueva semántica cultural de la memoria histórica en España a comienzos del siglo XXI», en Von TschilschKe, C., Schmelzer, D. (Eds.), Docuficción. Enlaces entre ficción y no-ficción en la cultura española actual, Vervuert / Iberoamericana, Frankfurt am Main / Madrid, 2010, pp.249-264.

\section{Documentales}

Agudo, M. (Dirección y guion), Guillena 1937, Intermedia producciones en coproducción con Canal Sur, 2013.

AlfoRJA, I., El cementerio de las botellas, -K Egindako Dokumentala, 2008.

Armengou, M., Belis, R. (Guión y dirección), Las fosas del silencio, «30 Minuts», TV3, 2003.

CArracedo, A., BAhar, R., El silencio de otros, Semilla Verde Productions / Lucernam Films / American Documentary POV / Independent Television Service / Latino Public Broadcasting (LPB) / El Deseo, España, 2018.

Domingo, A., Bernaola, I. (Guión y dirección), Las fosas del olvido, SÁnchez PRIETO, I. (Realización), «Documentos TV», RTVE, 2004.

Jiménez ReAL, A., Sombra en el paraíso, Malaparte Producciones, Málaga, 2009. LóPEZ, I. (Guión), Un silencio roto, Troyano, J. M. (Imagen), Durán, M. (Edición), «Este Mes», Canal Sur Televisión, 2004.

TeIXIDOR, P., Cunetas, Coming Soon Films, Barcelona, 2017.

\section{Referencias musicales}

ARnal, María; BAgÉs, Marcel, 45 cerebros y 1 corazón, producido por Fina Estampa, 2017. 
BARRICADA, La tierra está sorda, con un libreto de 184 páginas, Dro East West, 2009.

Guerra, P., 30 años, Sony Music, 2013.

LA RAIZ, Entre poetas y presos, editado por Propaganda pel Fet, producido por La Raíz y Roger Garcia, La Cañada, Valencia, 2016.

SócAm, L., Verdades escondidas, producido por la Cooperativa de Autores Utopía Producciones, para la A.P.R.M.H 19 Mujeres de Guillena; Patrocinado por la Consejería de Justicia de la Junta de Andalucía (Comisario de la Memoria Histórica) y el Ayuntamiento de Guillena, Sevilla, 2010.

\section{Financiación}

El presente artículo se realiza dentro del proyecto «SUBTIERRO: Exhumaciones de fosas comunes y derechos humanos en perspectiva histórica, transnacional y comparada», cuyo Investigador Principal es Francisco Ferrándiz (CSIC), MINECO CSO2015-66104-R.

\section{Datos de la Autora}

Queralt Solé Barjau es doctora en Historia Contemporánea por la Universitat de Barcelona (2008). Tiene cinco libros publicados y dos editados, especializándose como investigadora en el periodo de la Guerra Civil y el Franquismo, en especial en los ámbitos de represión y violencia política. Ha publicado artículos en diversas revistas indizadas en RESH, CINDOC, LATINDEX, SCOPUS o CARHUS+ y colaborado en diversos libros de autoría coral del período citado. Algunas de las revistas en las que ha publicado son: Hispania Nova. Revista de Historia Contemporánea, Afers, fulls de recerca i pensament, Ausa, Bulletin ofSpanish Studies, Cercles, Revista d'història cultural, Hispania-CSIC, Munibe o Human Remains. Participa en congresos nacionales e internacionales, donde también ha sido invitada como ponente. Imparte docencia en Grado (de Historia y de Arqueología) y en Máster oficial (de Historia Contemporánea), así como el Máster de la UNED "Memoria Social y derechos humanos: Ciencias sociales y forenses ante los conflictos contemporáneos". 